\title{
Fibrotic focus and hypoxia in male breast cancer
}

\author{
Robert Kornegoor ${ }^{1}$, Anoek HJ Verschuur-Maes ${ }^{1}$, Horst Buerger ${ }^{2}$, Marieke CH Hogenes ${ }^{3}$, \\ Peter C de Bruin ${ }^{4}$, Joost J Oudejans ${ }^{5}$, Bernd Hinrichs ${ }^{6}$ and Paul J van Diest ${ }^{1}$ \\ ${ }^{1}$ Department of Pathology, University Medical Center Utrecht, Utrecht, The Netherlands; ${ }^{2}$ Institute of \\ Pathology, Paderborn, Germany; ${ }^{3}$ Laboratory for Pathology East Netherlands, Enschede, The Netherlands; \\ ${ }^{4}$ Department of Pathology, St Antonius Hospital, Nieuwegein, The Netherlands; ${ }^{5}$ Department of Pathology, \\ Diakonessenhuis, Utrecht, The Netherlands and ${ }^{6}$ Center of Pathology and Cytodiagnostic, Cologne, Germany
}

\begin{abstract}
Fibrotic focus is a scar-like lesion near the center of a carcinoma and has been associated with high-grade, lymph node metastases and poor survival in female breast cancers. Hypoxia is suggested to be the crucial link between fibrotic focus and aggressive tumor phenotype and is also itself a poor prognostic marker. We here set out to study fibrotic focus and hypoxia in male breast cancer for the first time. In a group of $\mathbf{1 3 4}$ male breast cancer patients, the presence and size of a fibrotic focus and the expression of three hypoxia-related immunohistochemical stainings, hypoxia-inducible factor- $1 \alpha$, carbonic anhydrase IX and Glut-1 were studied in correlation with clinicopathological features and prognosis. Fibrotic focus was seen in $25 \%$ of the male breast cancer cases and was correlated with hypoxia-inducible factor- $1 \alpha$ overexpression $(P=0.023)$, high grade $(P=0.005)$, high mitotic activity $(P=0.005)$ and lymph node metastases $(P=0.037)$. Hypoxia-inducible factor- $1 \alpha-$ positive tumors were more often high grade $(P=0.003)$ and HER2 amplified $(P=0.005)$. Glut-1 expression was also more common in grade 3 tumors $(P=0.038)$, but no association between carbonic anhydrase IX and any clinicopathological feature was found. Fibrotic focus $>8 \mathrm{~mm}$ and hypoxia-inducible factor- $1 \alpha$ overexpression were correlated with decreased patients' outcome $(P=0.035$ and 0.008 , respectively). Hypoxia-inducible factor$1 \alpha$ overexpression was an independent and the most powerful predictor of survival in multivariate analysis $(P=0.029$; hazard ratio 2.5). In conclusion, the presence of a fibrotic focus is associated with hypoxia-inducible factor- $1 \alpha$ overexpression, and both are associated with aggressive tumor phenotype and poor survival in male breast cancer. These markers seem to have similar clinical importance as previously reported in female breast cancer.
\end{abstract}

Modern Pathology (2012) 25, 1397-1404; doi:10.1038/modpathol.2012.101; published online 8 June 2012

Keywords: fibrotic focus; hypoxia; male breast cancer; prognosis

Male breast cancer is uncommon and represents $<1 \%$ of all breast cancers. ${ }^{1}$ Large series in male breast cancer are lacking and much of the knowledge is generalized from breast cancer in female subjects. The limited data published on male breast cancer indicate that there are genetic and phenotypic differences between male and female breast cancer. ${ }^{2-6}$ Initially, prognosis in men was claimed to be poor with higher incidence of lymph node metastases at the time of discovery, but more recent

Correspondence: Professor PJ van Diest, MD, PhD, Department of Pathology, University Medical Center Utrecht, PO Box 85500, 3508 GA Utrecht, The Netherlands.

E-mail: p.j.vandiest@umcutrecht.nl

Received 13 February 2012; revised 19 April 2012; accepted 19 April 2012; published online 8 June 2012 studies showed that prognosis of male and female breast cancers corrected for stage and age is similar. $^{7-9}$ Although tumor size and lymph node status are independent prognosticators in male breast cancer, ${ }^{9,10}$ there still is a need for more accurate outcome predictors of male breast cancer.

A fibrotic focus is a scar-like lesion consisting of an area of mainly collagen and fibroblasts, often located near the center of a carcinoma. Fibrotic focus is associated with poor survival in female breast cancer and with high grade, high mitotic activity, lymph node metastases and HER2 overexpression. ${ }^{11-14}$ In lymph node-negative female breast cancer patients, fibrotic focus along with mitotic activity index was the most important prognostic factor. ${ }^{15}$ It has been claimed that it is an easily assessable histological determinant that 
should be incorporated in histopathological reports. ${ }^{15,16}$ Fibrotic focus has extensively been studied in female breast cancer, but in other malignancies, like carcinomas of the lung, pancreas and colon, fibrotic focus also appeared to be a useful marker with prognostic implications. ${ }^{17-19}$ Hypoxia is thought to be the crucial link between fibrotic focus and tumor phenotype and progression. Fibroblasts in fibrotic focus and tumor cells in carcinomas with fibrotic focus express hypoxia-inducible factor- $1 \alpha$ (HIF-1 $\alpha$ ) and carbonic anhydrase IX (CAIX), two hypoxiarelated factors. ${ }^{20,21}$ Expression of these markers in female breast cancer tumor cells has also been correlated with high grade and decreased survival. ${ }^{22-26}$

The incidence, clinicopathological correlations and prognostic implications of fibrotic focus and hypoxia had not yet been studied in male breast cancer, which was the aim of this study.

\section{Materials and methods}

\section{Patient Material}

In this study, we used a previously described group of male breast cancer. ${ }^{27}$ This group is composed of 134 consecutive cases from 1986 to 2010, collected from four different pathology labs in The Netherlands (St Antonius Hospital, Nieuwegein, $n=28$; Diakonessenhuis, Utrecht, $n=22$; University Medical Center Utrecht, Utrecht, $n=23$; and Laboratory for Pathology, East Netherlands, $n=40$ ) and two hospitals in Germany (Paderborn, $n=8$ and Cologne, $n=13$ ). The age ranged from 32 to 89 years (average: 66 years). Tumor size ranged from 0.4 to $5.5 \mathrm{~cm}$ (average: $2.1 \mathrm{~cm}$ ). In four cases, tumor size was not recorded. In $84 \%$ lymph node status was known and $54 \%$ of these patients had lymph node metastases (including isolated tumor cells; $n=4$ ). The majority of cases were (according to the WHO) invasive ductal carcinomas (90\%), with some lobular $(n=3)$, mixed type (ductal/lobular; $n=2)$, invasive cribriform $(n=2)$, papillary $(n=2)$, mucinous $(n=2)$, invasive micropapillary $(n=1)$ and adenoid cystic carcinomas $(n=1)$. Most tumors were grade II $(40 \%)$ and grade III $(36 \%) .{ }^{28}$ Mitotic activity index per $2 \mathrm{~mm}^{2}$ was assessed as before. ${ }^{29}$ Estrogen receptor (ER) was positive in 94\% (125/133) of the cases, and progesterone receptor (PR) was also common (90/133; 68\%). In one case hormone receptor status was missing. HER2 overexpression/amplification was rare $(4 / 134 ; 3 \%)$.

\section{Fibrotic Focus}

Fibrotic focus was defined following the criteria first described by Hasebe et al. ${ }^{11}$ In short, fibrotic focus is a scar-like area with a radially expending fibrosclerotic core, usually in the center of a carcinoma (Figure 1). It consists of variably dense and

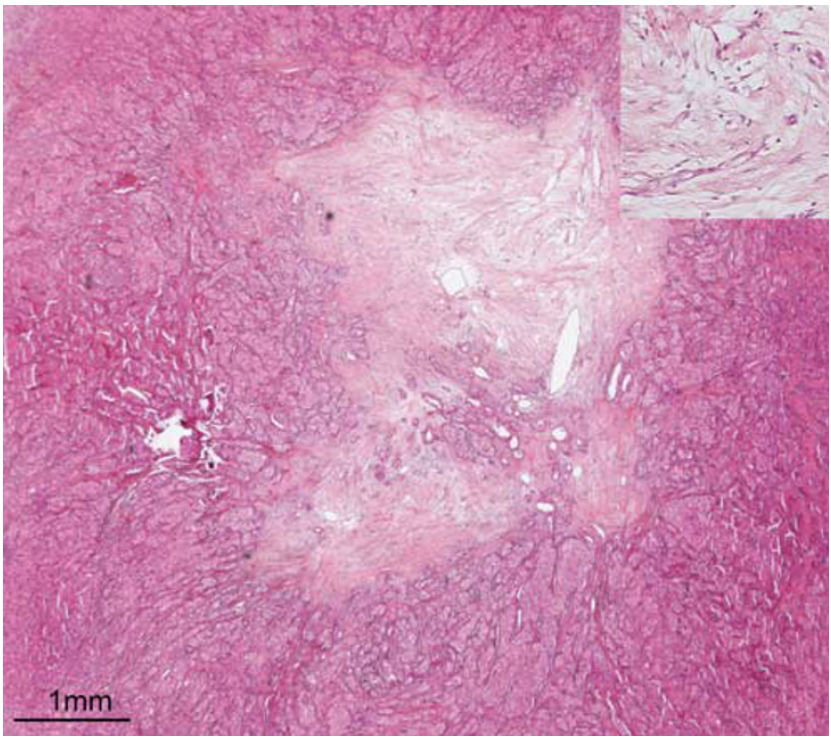

Figure 1 Invasive ductal carcinoma with a fibrotic focus. This example demonstrates the histological appearance of a fibrotic focus with a fibrosclerotic core and disorganized vessels.

sometimes hyalinized collagen bundles and fibroblasts. A diameter of at least $1 \mathrm{~mm}$ was required and fibrotic areas smaller than $3 \mathrm{~mm}$ did not contain tumor cells. With increasing size, solid nest and strands of tumor cells were more often seen within a fibrotic focus. Sometimes remnants of necrosis were seen, but foci of necrosis without a fibrotic core were not classified as fibrotic focus. Fibrotic focus was surrounded by more cellular parts of infiltrating carcinoma. In case secondary changes were seen indicating core needle biopsy artifacts, like the presence of a needle track or fat necrosis, the fibrotic areas were not scored as a fibrotic focus. The presence and size of a fibrotic focus was recorded. The size of a fibrotic focus was dichotomized using a threshold of $>8 \mathrm{~mm}$ and the fibrotic focus/tumor diameter ratio was also calculated (threshold $>1 / 3$ ), for correlation with patients' outcome. ${ }^{2,15}$

\section{Immunohistochemistry}

Immunohistochemical stainings were performed using tissue microarray (TMA) blocks, which were constructed as described before. ${ }^{27}$ In short, hematoxylin- and eosin- (HE) stained slides were used to identify representative tumor areas. From the areas richest in tumor cells, three 0.6-mm punch biopsies from formalin-fixed and paraffin-embedded tissue blocks were obtained and embedded in a recipient paraffin block, using a precision tissue array instrument (Beecher Instruments, Sun Prairie, WI, USA). Sections $(4 \mu \mathrm{m})$ were cut and stained for Glut-1, HIF- $1 \alpha$ and CAIX at the University Medical Center Utrecht. Glut-1 stainings were performed using a Bond-max automated immunostainer (Leica Microsystems, Wetzlar, Germany) and the stainings 
for HIF-1 $\alpha$ and CAIX were carried out manually as before (Table 1). ${ }^{30}$ Antigen retrieval for Glut-1 was carried out with epitope retrieval buffer 1, 20 min at $99^{\circ} \mathrm{C}$ (AR9961; Leica Microsystems). The slides were incubated with the primary antibody Glut-1 for $15 \mathrm{~min}$ at room temperature and afterwards with the Bond refine polymer kit (DS9800; Leica Microsystems). For CAIX antigen retrieval was performed in citrate buffer $\left(\mathrm{pH}=6.0\right.$, for $20 \mathrm{~min}$ at $\left.100^{\circ} \mathrm{C}\right)$. After incubation for $60 \mathrm{~min}$ at room temperature with the primary antibody, we used Powervision ready to use (poly-HRP-anti Ms/Rb/RtlgG biotin free; ImmunoLogic, ImmunoVision Technologies, Brisbane CA, USA) for the recognition of the primary antibody. EDTA buffer $\left(\mathrm{pH}=9.0\right.$, for $20 \mathrm{~min}$ at $\left.100^{\circ} \mathrm{C}\right)$ was used for antigen retrieval for HIF-1 $\alpha$. Slides were incubated with the primary antibody HIF-1 $\alpha$ overnight at $4{ }^{\circ} \mathrm{C}$. For detection of the primary antibody, Novolink polymer was used (Novocastra Laboratories Ltd, Newcastle Upon Tyne, UK). All slides were developed with diaminobenzidine. Formalinfixed and paraffin-embedded clear-cell renal cell carcinoma, placenta and breast carcinoma tissue were used as positive control for CAIX, Glut-1 and HIF-1 $\alpha$, respectively. Appropriate negative control steps were used throughout the procedure. All stainings were scored by two experienced observers (PJvD/RK).

For HIF-1 $\alpha$, mean nuclear staining percentages of the available punches were used, regarding $5 \%$ or more tumor cells with nuclear staining as positive. ${ }^{22}$ Any clear membrane staining in the Glut-1 and
CAIX was scored positive (Figure 2). For all markers, two patterns of staining were scored as before: ${ }^{25}$ a diffuse pattern with staining throughout tumor cells and the perinecrotic pattern with staining restricted to perinecrotic tumor cells.

\section{Statistics}

Prognostic information was requested from the Integral Cancer Registration (The Netherlands; IKNL). Outcome data were available for 101 cases $(101 / 134 ; 75 \%)$ with a median follow-up of 5.7 years (range 0.1-20.3 years). Therefore, survival analysis was based on 5 years survival rates.

Statistical calculations were performed using SPSS for Windows version 15.0. Pearson's $\chi^{2}$ (or Fisher's exact test when appropriate) was used to evaluate correlation between fibrotic focus and the clinicopathological features age ( $>50$ years), size $(>2 \mathrm{~cm})$, lymph node status, tubule formation, nuclear grade, mitotic activity ( $>8$ mitoses per $2 \mathrm{~mm}^{2}$ ), histological grade (grade $1 / 2$ vs 3 ) and ER, PR and HER2 status. To compare mean age, size and number of mitoses, ANOVA was performed. Spearman's $\rho$ was used to calculate correlations between the hypoxia-related immunohistochemical markers. Expression of these markers was also correlated with clinicopathological features using Pearson's $\chi^{2}$ and ANOVA. Two-sided $P$-values $<0.05$ were regarded significant. For univariate survival analysis, Kaplan-Meier curves were plotted and analyzed

Table 1 Overview of the hypoxia-related antibodies and tissue-processing details used to characterize male breast cancer

\begin{tabular}{|c|c|c|c|c|c|c|}
\hline Antigen & Type & Source & Dilution & $A R$ & Incubation time antibody & Positive control \\
\hline Glut-1 & Polyclonal & DAKO & $1: 200$ & Citrate & $15 \mathrm{~min}$ & Placenta \\
\hline CAIX & Polyclonal & Abcam & 1:1000 & Citrate & $1 \mathrm{~h}$ & Renal cell carcinoma \\
\hline HIF- $1 \alpha$ & Monoclonal & BD Bioscience & $1: 50$ & EDTA & Overnight $\left(4^{\circ} \mathrm{C}\right)$ & Breast carcinoma \\
\hline
\end{tabular}

AR: antigen retrieval.

DAKO, Glostrup, Denmark; Abcam, Cambridge Science Park, Cambridge, UK; BD Bioscience, Franklin Lakes, NJ, USA.

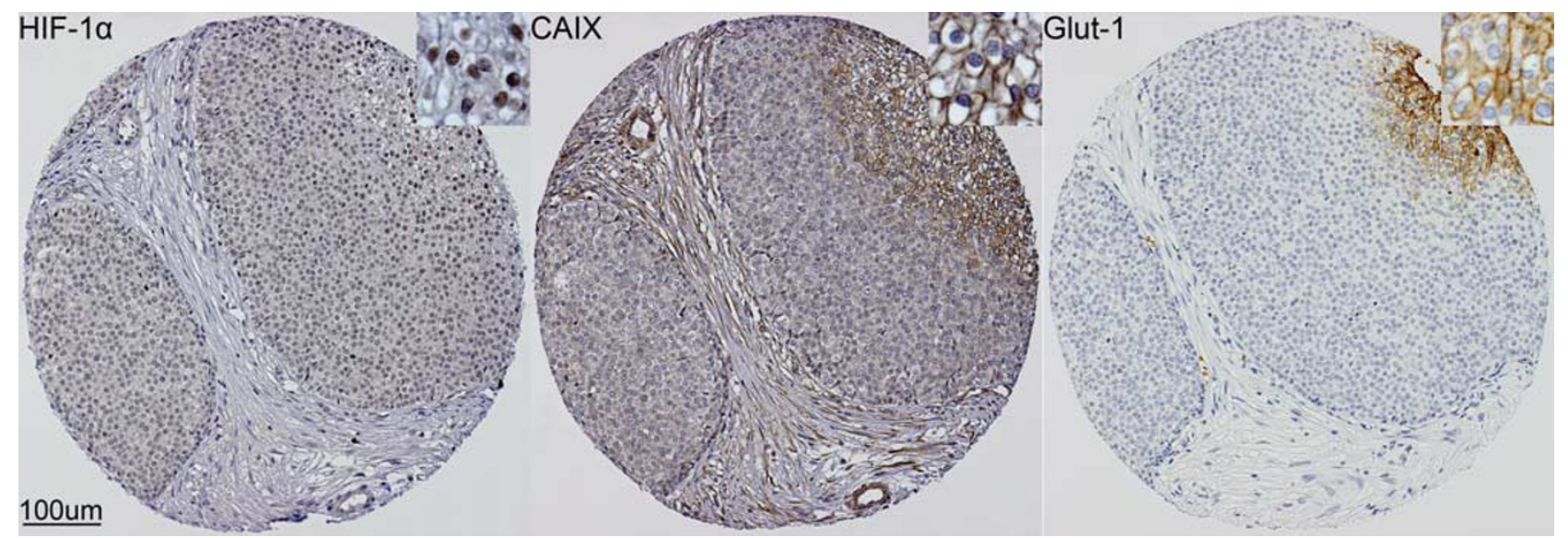

Figure 2 Tissue microarray slide stained for hypoxia-inducible factor- $1 \alpha$ (HIF-1 $\alpha$ ), carbonic anhydrase IX (CAIX) and glucose transporter-1 (Glut-1), all scored positive in the same case of male breast cancer. 
Table 2 Clinicopathological features in 134 cases of male breast cancers with and without fibrotic focus

\begin{tabular}{|c|c|c|c|c|c|}
\hline Feature & Grouping & All cases (\%) & Fibrotic focus present (\%) & Fibrotic focus absent (\%) & P-value \\
\hline Tumor size & $\begin{array}{l}<2.0 \mathrm{~cm} \\
>2.0 \mathrm{~cm}\end{array}$ & $\begin{array}{l}65(50 \%) \\
65(50 \%)\end{array}$ & $\begin{array}{l}14(41 \%) \\
20(59 \%)\end{array}$ & $\begin{array}{l}51(53 \%) \\
45(47 \%)\end{array}$ & 0.231 \\
\hline Tubule formation & $\begin{array}{c}>75 \% \\
10-75 \% \\
<10 \%\end{array}$ & $\begin{array}{l}13(10 \%) \\
55(41 \%) \\
66(49 \%)\end{array}$ & $\begin{array}{c}0(0 \%) \\
12(35 \%) \\
22(65 \%)\end{array}$ & $\begin{array}{l}13(13 \%) \\
43(43 \%) \\
44(44 \%)\end{array}$ & 0.030 \\
\hline Nuclear atypia & $\begin{array}{l}\text { Mild } \\
\text { Moderate } \\
\text { Severe }\end{array}$ & $\begin{array}{l}12(9 \%) \\
80(60 \%) \\
42(31 \%)\end{array}$ & $\begin{array}{c}0(0 \%) \\
19(56 \%) \\
15(44 \%)\end{array}$ & $\begin{array}{l}12(12 \%) \\
61(61 \%) \\
27(27 \%)\end{array}$ & 0.038 \\
\hline Mitoses $/ 2 \mathrm{~mm}^{2}$ & $\begin{array}{c}\text { Mean } \\
0-8 \\
>8\end{array}$ & $\begin{array}{c}11 \\
61(46 \%) \\
73(54 \%)\end{array}$ & $\begin{array}{c}15 \\
12(35 \%) \\
22(65 \%)\end{array}$ & $\begin{array}{c}10 \\
49(49 \%) \\
51(51 \%)\end{array}$ & $\begin{array}{l}0.005 \\
0.166\end{array}$ \\
\hline Grade & $\begin{array}{l}\text { I/II } \\
\text { III }\end{array}$ & $\begin{array}{l}86(64 \%) \\
48(36 \%)\end{array}$ & $\begin{array}{l}15(44 \%) \\
19(56 \%)\end{array}$ & $\begin{array}{l}71(71 \%) \\
29(29 \%)\end{array}$ & 0.005 \\
\hline Lymph node metastases & $\begin{array}{l}\text { Absent } \\
\text { Present }\end{array}$ & $\begin{array}{l}51(46 \%) \\
61(54 \%)\end{array}$ & $\begin{array}{r}8(29 \%) \\
20(71 \%)\end{array}$ & $\begin{array}{l}43(51 \%) \\
41(49 \%)\end{array}$ & 0.037 \\
\hline ER & $\begin{array}{l}- \\
+\end{array}$ & $\begin{array}{c}8(6 \%) \\
125(94 \%)\end{array}$ & $\begin{array}{c}1(3 \%) \\
33(97 \%)\end{array}$ & $\begin{array}{c}7(7 \%) \\
92(93 \%)\end{array}$ & 0.679 \\
\hline PR & $\begin{array}{l}- \\
+\end{array}$ & $\begin{array}{l}43(32 \%) \\
90(68 \%)\end{array}$ & $\begin{array}{l}13(38 \%) \\
21(62 \%)\end{array}$ & $\begin{array}{l}30(30 \%) \\
69(70 \%)\end{array}$ & 0.394 \\
\hline HER2 & $\begin{array}{l}- \\
+\end{array}$ & $\begin{array}{c}130(97 \%) \\
4(3 \%)\end{array}$ & $\begin{array}{c}32(94 \%) \\
2(6 \%)\end{array}$ & $\begin{array}{c}98(98 \%) \\
2(2 \%)\end{array}$ & 0.266 \\
\hline
\end{tabular}

with the log-rank test. Multivariate survival analysis was carried out with Cox regression, including the variables that were significant in univariate survival analysis.

\section{Results}

Histopathological features of the 134 cases of male breast cancers with and without fibrotic focus are summarized in Table 2. Fibrotic focus was seen in $25 \%(34 / 134)$ of the cases and was significantly associated with high nuclear $(P=0.038)$ and histological grade $(P=0.005)$, few or no tubule formation $(P=0.030)$ and presence of lymph node metastases $(P=0.037)$. Tumors with fibrotic focus showed significantly higher mean mitotic activity with on an average 15 mitoses vs 10 mitoses per $2 \mathrm{~mm}^{2}$ in tumors with and without fibrotic focus $(P=0.005)$. However, in case a cutoff value of 8 mitoses was used, no significant difference was found $(P=0.166)$ No correlation was found between fibrotic focus and tumor size. Mean age was similar and no significant differences were found in ER, PR and HER2 status between tumors with and without fibrotic focus.

HIF-1 $\alpha$, CAIX and Glut-1 showed overexpression in, respectively, $27 \%$ (34/125), $7 \%$ (9/132) and 31\% (41/131) of cases (some cases were lost on the TMA slides). A diffuse staining pattern was most commonly seen for these markers. HIF- $1 \alpha$ showed diffuse expression in $22 \%(27 / 125)$ of the cases, which represents $79 \%$ of all HIF- $1 \alpha$-positive tumors. There was a significant correlation between overexpression of HIF-1 $\alpha$ and the other two hypoxia-related proteins Glut-1 $(P<0.001$; correlation coefficient: $0.32)$ and $\operatorname{CAIX}(P=0.034$; correlation coefficient: 0.21$)$. Correlations between expression of the hypoxia- related markers and clinicopathological features are presented in Table 3 . HIF- $1 \alpha$-positive tumors showed higher mean mitotic count (13 vs 10 mitoses per $2 \mathrm{~mm}^{2}$ ), but this did not reach significance $(P=0.086)$. HIF- $1 \alpha$ overexpression was significantly more common in grade 3 tumors $(P=0.003)$. All HER2-amplified tumors $(n=4)$ were also HIF-1 $\alpha$ positive $(P=0.005)$. In case only diffuse staining of more than $5 \%$ of the tumor cells was regarded positive, there was a significantly increased number of mitoses in HIF- $1 \alpha$-positive tumors $(P=0.038)$ and an even stronger correlation between HIF- $1 \alpha$ and high histological grade $(P<0.001)$. A diffuse staining pattern of HIF- $1 \alpha$ was also associated with the presence of fibrotic focus $(P=0.023)$. When subgroup analysis was performed for tumors with and without lymph node metastases, we found that the aggressive phenotype of HIF- $1 \alpha$-positive tumors was particularly seen in the group of male breast cancer patients with lymph node metastases, as in the lymph node-negative group no correlation with mitotic count and histological grade was seen. Glut-1 overexpression was correlated with high mitotic count $(>8 ; P=0.014)$ and with high histological grade $(P=0.038)$. CAIX overexpression was rare $(n=9)$ compared to the other two hypoxiarelated markers and no correlation with any clinicopathological features was seen.

In Table 4 and Figure 3 univariate survival rates are presented according to clinicopathological features, presence of a fibrotic focus and expression of hypoxia-related markers. Grade $3(P=0.027)$, high mitotic count $(>8 ; P=0.015)$ and large tumor size $(>2.0 \mathrm{~cm} ; P=0.036)$ were predictors of poor prognosis. The presence of a fibrotic focus or the relative size of a fibrotic focus (fibrotic focus/tumor size) did not influence patients' outcome. However, fibrotic 
Table 3 Clinicopathological features of male breast cancer cases with and without staining of HIF- $1 \alpha$, CAIX and Glut-1

\begin{tabular}{|c|c|c|c|c|c|c|c|}
\hline \multirow[t]{2}{*}{ Feature } & \multirow[t]{2}{*}{ Grouping } & \multicolumn{2}{|c|}{$H I F-1 \alpha$} & \multicolumn{2}{|c|}{ CAIX } & \multicolumn{2}{|c|}{ Glut-1 } \\
\hline & & $+(\%)$ & $-(\%)$ & $+(\%)$ & $-(\%)$ & $+(\%)$ & $-(\%)$ \\
\hline Tumor size & $\begin{array}{l}<2.0 \mathrm{~cm} \\
>2.0 \mathrm{~cm}\end{array}$ & $\begin{array}{l}14(44 \%) \\
18(56 \%)\end{array}$ & $\begin{array}{l}48(54 \%) \\
41(46 \%)\end{array}$ & $\begin{array}{l}6(75 \%) \\
2(25 \%)\end{array}$ & $\begin{array}{l}57(47 \%) \\
63(53 \%)\end{array}$ & $\begin{array}{l}19(47 \%) \\
21(53 \%)\end{array}$ & $\begin{array}{l}44(51 \%) \\
43(49 \%)\end{array}$ \\
\hline Mitoses $/ 2 \mathrm{~mm}^{2}$ & $\begin{array}{c}\text { Mean } \\
0-8 \\
>8\end{array}$ & $\begin{array}{c}13 \\
12(35 \%) \\
22(65 \%)\end{array}$ & $\begin{array}{c}10 \\
46(51 \%) \\
45(49 \%)\end{array}$ & $\begin{array}{c}12 \\
2(22 \%) \\
7(78 \%)\end{array}$ & $\begin{array}{c}11 \\
58(47 \%) \\
65(53 \%)\end{array}$ & $\begin{array}{c}13 \\
12(29 \%) \\
29(71 \%)\end{array}$ & $\begin{array}{c}10 \\
47(52 \%) \\
43(48 \%)^{*}\end{array}$ \\
\hline Grade & $\begin{array}{c}\mathrm{I} / \mathrm{II} \\
\mathrm{III}\end{array}$ & $\begin{array}{l}15(44 \%) \\
19(56 \%)\end{array}$ & $\begin{array}{l}66(73 \%) \\
25(27 \%)^{*}\end{array}$ & $\begin{array}{l}6(67 \%) \\
3(33 \%)\end{array}$ & $\begin{array}{l}79(64 \%) \\
44(36 \%)\end{array}$ & $\begin{array}{l}21(51 \%) \\
20(49 \%)\end{array}$ & $\begin{array}{l}63(70 \%) \\
27(30 \%)^{*}\end{array}$ \\
\hline LN meta & $\begin{array}{l}\text { Absent } \\
\text { Present }\end{array}$ & $\begin{array}{l}11(41 \%) \\
16(59 \%)\end{array}$ & $\begin{array}{l}38(50 \%) \\
38(50 \%)\end{array}$ & $\begin{array}{l}3(43 \%) \\
4(57 \%)\end{array}$ & $\begin{array}{l}47(46 \%) \\
56(54 \%)\end{array}$ & $\begin{array}{l}16(46 \%) \\
19(54 \%)\end{array}$ & $\begin{array}{l}34(46 \%) \\
40(54 \%)\end{array}$ \\
\hline ER & $\begin{array}{l}- \\
+\end{array}$ & $\begin{array}{c}0 \\
34(100 \%)\end{array}$ & $\begin{array}{c}7(8 \%) \\
84(92 \%)\end{array}$ & $9 \begin{array}{c}0 \\
(100 \%)\end{array}$ & $\begin{array}{c}7(6 \%) \\
116(94 \%)\end{array}$ & $\begin{array}{c}0 \\
41(100 \%)\end{array}$ & $\begin{array}{c}7(8 \%) \\
83(92 \%)\end{array}$ \\
\hline PR & + & $\begin{array}{l}11(32 \%) \\
23(68 \%)\end{array}$ & $\begin{array}{l}29(32 \%) \\
62(68 \%)\end{array}$ & $\begin{array}{l}2(22 \%) \\
7(78 \%)\end{array}$ & $\begin{array}{l}41(33 \%) \\
82(67 \%)\end{array}$ & $\begin{array}{l}12(29 \%) \\
29(71 \%)\end{array}$ & $\begin{array}{l}31(34 \%) \\
59(66 \%)\end{array}$ \\
\hline HER2 & $\begin{array}{l}- \\
+\end{array}$ & $\begin{array}{r}30(88 \%) \\
4(12 \%)\end{array}$ & $\begin{array}{c}91(100 \%) \\
0^{*}\end{array}$ & $\begin{array}{c}9(100 \%) \\
0\end{array}$ & $\begin{array}{c}119(97 \%) \\
4(3 \%)\end{array}$ & $\begin{array}{c}39(95 \%) \\
2(5 \%)\end{array}$ & $\begin{array}{c}88(98 \%) \\
2(2 \%)\end{array}$ \\
\hline
\end{tabular}

LN meta: lymph node metastases.

* Significantly different $(P<0.05)$.

Table 4 Univariate (log-rank) survival rates of 101 male breast cancer patients according to classic clinicopathological features, fibrotic focus and hypoxia-related markers

\begin{tabular}{|c|c|c|c|}
\hline \multirow[t]{2}{*}{ Feature } & \multirow[t]{2}{*}{ Grouping } & \multicolumn{2}{|c|}{ 5-Year survival } \\
\hline & & Survival rate (\%) & P-value \\
\hline Tumor size & $\begin{array}{l}<2.0 \mathrm{~cm} \\
>2.0 \mathrm{~cm}\end{array}$ & $\begin{array}{l}79 \\
59\end{array}$ & 0.036 \\
\hline Mitoses $/ 2 \mathrm{~mm}^{2}$ & $\begin{array}{l}0-8 \\
>8\end{array}$ & $\begin{array}{l}81 \\
57\end{array}$ & 0.015 \\
\hline Grade & $\begin{array}{l}\text { I/II } \\
\text { III }\end{array}$ & $\begin{array}{l}77 \\
53\end{array}$ & 0.027 \\
\hline Lymph node metastases & $\begin{array}{l}\text { Absent } \\
\text { Present }\end{array}$ & $\begin{array}{l}82 \\
65\end{array}$ & 0.132 \\
\hline Fibrotic focus & $\begin{array}{l}\text { Absent } \\
\text { Present }\end{array}$ & $\begin{array}{l}65 \\
75\end{array}$ & 0.581 \\
\hline $\begin{array}{l}\text { Fibrotic focus/tumor } \\
\text { size ratio }\end{array}$ & $\begin{array}{l}\leq 1 / 3 \\
>1 / 3\end{array}$ & $\begin{array}{l}69 \\
61\end{array}$ & 0.447 \\
\hline Size of fibrotic focus & $\begin{array}{l}\leq 8 \mathrm{~mm} \\
>8 \mathrm{~mm}\end{array}$ & $\begin{array}{l}70 \\
43\end{array}$ & 0.035 \\
\hline HIF- $1 \alpha$ & $\begin{array}{l}- \\
+\end{array}$ & $\begin{array}{l}75 \\
51\end{array}$ & 0.008 \\
\hline CAIX & $\begin{array}{l}- \\
+\end{array}$ & $\begin{array}{l}67 \\
83\end{array}$ & 0.448 \\
\hline Glut-1 & $\begin{array}{l}- \\
+\end{array}$ & $\begin{array}{l}68 \\
67\end{array}$ & 0.797 \\
\hline
\end{tabular}

focus $>8 \mathrm{~mm}$ was correlated with decreased survival $(P=0.035)$. HIF- $1 \alpha$ overexpression was also a marker for adverse patients' outcome $(P=0.008)$. When HIF-1 $\alpha$ expression was separated into perinecrotic and diffuse staining, perinecrotic staining showed the most unfavorable patients' outcome (survival rate: $40 \%$ ), compared to a survival rate of 54 and $75 \%$ for diffuse HIF- $1 \alpha$ staining and HIF- $1 \alpha-$ negative tumors $(P=0.014)$. However, these results need to be interpreted with caution because there were only five cases with perinecrotic HIF-1 $\alpha$ staining with available follow-up data and therefore no significant difference was found in case perinecrotic and diffuse HIF- $1 \alpha$ staining were compared. The other hypoxia-related markers (CAIX and Glut1) did not correlate with patients' outcome. In the subgroups of lymph node-positive and -negative patients, no prognostic correlations were found.

In Cox regression, HIF-1 $\alpha$ overexpression appeared to be an independent and the most powerful predictor of patients' survival $(P=0.029$; hazard ratio 2.5). Tumor size was the only other independent prognosticator in this model $(P=0.047$; hazard ratio 2.4) and fibrotic focus $>8 \mathrm{~mm}$ was not retained as an independent prognostic factor (Table 5).

\section{Discussion}

Fibrotic focus is considered an easily assessable histological determinant with prognostic implications in several malignancies. Hypoxia is deemed crucial in the formation of fibrotic focus and is also on its own a marker for aggressive course in cancer. This study is the first to investigate the clinicopathological relevance of fibrotic focus and hypoxia in male breast cancer. We demonstrate that fibrotic focus is associated with the overexpression of HIF$1 \alpha$ and that both are associated with aggressive tumor phenotype. Fibrotic focus $>8 \mathrm{~mm}$ and HIF- $1 \alpha$ overexpression were correlated with decreased survival. HIF- $1 \alpha$ was even an independent prognosticator.

Our findings are consistent with previous studies in female breast cancer, which demonstrated that in female breast cancer fibrotic focus is also correlated with high histological grade, high mitotic activity, presence of lymph node metastases and adverse patients' outcome. ${ }^{11,12,14}$ However, in this study fibrotic focus $>8 \mathrm{~mm}$ was not an independent prognostic factor when tumor size and/or histological 

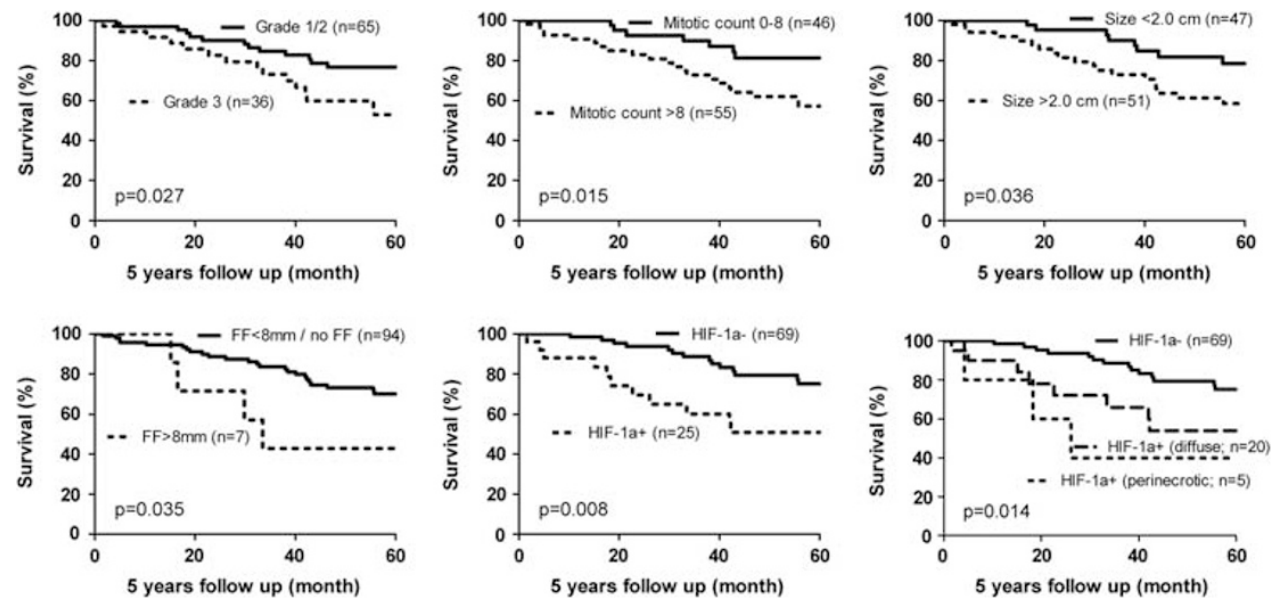

Figure 3 Kaplan-Meier survival curves according to histological grade, mitotic count, tumor size, the presence of a fibrotic focus $>8 \mathrm{~mm}$, hypoxia-inducible factor- $1 \alpha(\mathrm{HIF}-1 \alpha)$ overexpression and pattern of HIF- $1 \alpha$ overexpression.

Table 5 Multivariate survival analysis (Cox regression)

\begin{tabular}{lclc}
\hline Feature & Hazard ratio & $95 \%$ CI & P-value \\
\hline Tumor size & 2.4 & $1.0-5.9$ & 0.047 \\
Mitoses $/ 2 \mathrm{~mm}^{2}$ & 1.8 & $0.75-4.6$ & 0.182 \\
Grade & 1.2 & $0.36-4.0$ & 0.780 \\
Size of fibrotic focus & 1.9 & $0.59-5.9$ & 0.291 \\
HIF- $1 \alpha$ & 2.5 & $1.1-5.6$ & 0.029 \\
\hline
\end{tabular}

CI: confidence interval.

grade and/or mitotic count were taken into account. Although in female breast cancer fibrotic focus is also more often seen in large and HER2-positive tumors, ${ }^{11,12,14}$ we did not find such significant correlations in male breast cancer. In HER2-positive cancers, fibrotic focus was seen in $50 \%$, but because HER2 positivity was rare $(n=4)$, no significance was reached. Like in female breast cancer, no correlation was found between fibrotic focus on the one hand and ER status and age on the other. ${ }^{11}$

The role of fibrotic focus in tumor phenotype and progression may be explained by the presence of hypoxic fibroblast and tumor cells with the expression of HIF- $1 \alpha$ and CAIX. ${ }^{20,21}$ Low oxygen induces hypoxia-modulated gene expression, with transcription of HIF- $1 \alpha$, a key player in the adaptive process of cells that allow them to escape from dying during hypoxia. HIF- $1 \alpha$ induces transcription of genes that are involved in angiogenesis, cell survival, proliferation and promotes an aggressive tumor phenotype..$^{31,32}$ Several studies demonstrated high microvessel count and high microvessel density in tumors with fibrotic focus, especially in case a fibrotic focus is relatively large and harbors necrosis. ${ }^{13,14}$ The fibroblasts occupying a fibrotic focus are reported to be highly proliferative and have the ability to express proteinase, which is crucial for developing metastases. ${ }^{33-36}$

There was indeed a significant correlation between the presence of fibrotic focus and overexpression of
HIF-1 $\alpha$ in tumor cells, suggesting that hypoxia is important in fibrotic focus formation in male breast cancer as well, and confirming previous results in female breast cancer. ${ }^{21}$ Unlike previous studies, no association was found between CAIX expression and the presence of a fibrotic focus. ${ }^{20,21}$ We used TMA slides for high throughput and focal staining may therefore have been missed. However, usual correlations were found for HIF-1 $\alpha$ overexpression on TMAs, so differences in antibody and staining procedures may also play a role here.

Expression of HIF- $1 \alpha$ in tumor cells have been reported in a variety of malignancies. ${ }^{37}$ Our results are in line with studies in female breast cancer, which demonstrated that HIF- $1 \alpha$ overexpression was correlated with highly malignant phenotype and bad outcome. ${ }^{22-25}$ For the first time, we demonstrated that HIF- $1 \alpha$ overexpression is an independent predictor of survival in male breast cancer patients and could be used as an important prognosticator, more powerful in predicting adverse male breast cancer patients' outcome than classical clinicopathological features. The correlation between HER2 overexpression/amplification and HIF-1 $\alpha$ overexpression has been described in female breast cancer. ${ }^{22}$ HER2 is able to induce HIF- $1 \alpha$ synthesis, which depends on the activation of PI-3-kinase/ protein kinase B (PI3K-AKT) pathway. ${ }^{38}$ There are conflicting results regarding the prognostic relevance of HIF-1 $\alpha$ in female breast cancer groups with or without lymph node metastases. ${ }^{22,24}$ In our group of male breast cancer, aggressive phenotype associated with HIF-1 $\alpha$ overexpression was particularly seen in patients with lymph node metastases. However, survival analysis did not reveal prognostic differences for HIF-1 $\alpha$ in tumors with lymph node metastases alone. Furthermore in this study, a diffuse staining pattern of HIF- $1 \alpha$ was the strongest predictor of high malignant phenotype and the presence of a fibrotic focus. This could point to different pathways of HIF- $1 \alpha$ upregulation, which might be, in part, hypoxia independent and reflect 
oncogenic adaptations of tumor cells. However, perinecrotic staining of $\mathrm{HIF}-1 \alpha$ seems to be the strongest predictor of adverse patients' outcome, which is in line with findings in female breast cancer. $^{25}$ Conclusions concerning HIF-1 $\alpha$ staining patterns should be made with caution based on our results, because there were only a few cases $(n=7)$ with perinecrotic staining, which may have been underscored in TMA slides. ${ }^{39}$

The frequency of HIF-1 $\alpha$-overexpressing tumors in male breast cancer in this study is hard to compare with previously reported data in female breast cancer, because different methods and different cutoff values were used. In this study, 27\% (34/125) of the tumors were HIF-1 $\alpha$ positive, which is slightly lower compared to a previous study, reporting $34 \%$ (51/150) HIF-1 $\alpha$-positive female breast cancers, using a similar cutoff value of $5 \% .^{22}$ Further research is needed to investigate possible differences in the expression of hypoxia-related immunohistochemical markers between male and female breast cancers.

In conclusion, we demonstrate that fibrotic focus and HIF-1 $\alpha$ overexpression in male breast cancer are associated with high-grade tumors and poor prognosis and should be regarded as markers for aggressive behavior. These markers seem to have similar clinical importance as previously reported in female breast cancer.

\section{Disclosure/conflict of interest}

The authors declare no conflict of interest.

\section{References}

1 Jemal A, Siegel R, Xu J, et al. Cancer statistics, 2010. CA Cancer J Clin 2010;60:277-300.

2 Anderson WF, Jatoi I, Tse J, et al. Male breast cancer: a population-based comparison with female breast cancer. J Clin Oncol 2010;28:232-239.

3 Muir D, Kanthan R, Kanthan SC. Male versus female breast cancers. A population-based comparative immunohistochemical analysis. Arch Pathol Lab Med 2003;127:36-41.

4 Andre S, Pinto AE, Laranjeira C, et al. Male and female breast cancer-differences in DNA ploidy, p21 and p53 expression reinforce the possibility of distinct pathways of oncogenesis. Pathobiology 2007;74:323-327.

5 Johansson I, Nilsson C, Berglund P, et al. Highresolution genomic profiling of male breast cancer reveals differences hidden behind the similarities with female breast cancer. Breast Cancer Res Treat 2010; 129:747-760.

6 Callari M, Cappelletti V, De Cecco L, et al. Gene expression analysis reveals a different transcriptomic landscape in female and male breast cancer. Breast Cancer Res Treat 2010;127:601-610.

7 Joshi MG, Lee AK, Loda M, et al. Male breast carcinoma: an evaluation of prognostic factors contributing to a poorer outcome. Cancer 1996;77:490-498.
8 Marchal F, Salou M, Marchal C, et al. Men with breast cancer have same disease-specific and event-free survival as women. Ann Surg Oncol 2009;16:972-978.

9 Giordano SH, Cohen DS, Buzdar AU, et al. Breast carcinoma in men: a population-based study. Cancer 2004;101:51-57.

10 Cutuli B, Le-Nir CC, Serin D, et al. Male breast cancer. Evolution of treatment and prognostic factors. Analysis of 489 cases. Crit Rev Oncol Hematol 2010;73:246-254.

11 Hasebe T, Tsuda H, Hirohashi S, et al. Fibrotic focus in infiltrating ductal carcinoma of the breast: a significant histopathological prognostic parameter for predicting the long-term survival of the patients. Breast Cancer Res Treat 1998;49:195-208.

12 Hasebe T, Sasaki S, Imoto S, et al. Prognostic significance of fibrotic focus in invasive ductal carcinoma of the breast: a prospective observational study. Mod Pathol 2002;15:502-516.

13 Colpaert C, Vermeulen P, Jeuris W, et al. Early distant relapse in 'node-negative' breast cancer patients is not predicted by occult axillary lymph node metastases, but by the features of the primary tumour. J Pathol 2001;193:442-449.

14 Colpaert C, Vermeulen P, van Beest P, et al. Intratumoral hypoxia resulting in the presence of a fibrotic focus is an independent predictor of early distant relapse in lymph node-negative breast cancer patients. Histopathology 2001;39:416-425.

15 Baak JP, Colpaert CG, van Diest PJ, et al. Multivariate prognostic evaluation of the mitotic activity index and fibrotic focus in node-negative invasive breast cancers. Eur J Cancer 2005;41:2093-2101.

16 Van den Eynden GG, Colpaert CG, Couvelard A, et al. A fibrotic focus is a prognostic factor and a surrogate marker for hypoxia and (lymph)angiogenesis in breast cancer: review of the literature and proposal on the criteria of evaluation. Histopathology 2007;51: $440-451$.

17 Nishimura R, Hasebe T, Tsubono Y, et al. The fibrotic focus in advanced colorectal carcinoma: a hitherto unrecognized histological predictor for liver metastasis. Virchows Arch 1998;433:517-522.

18 Maeshima AM, Niki T, Maeshima A, et al. Modified scar grade: a prognostic indicator in small peripheral lung adenocarcinoma. Cancer 2002;95:2546-2554.

19 Couvelard A, O'Toole D, Leek R, et al. Expression of hypoxia-inducible factors is correlated with the presence of a fibrotic focus and angiogenesis in pancreatic ductal adenocarcinomas. Histopathology 2005;46: 668-676.

20 Colpaert CG, Vermeulen PB, Fox SB, et al. The presence of a fibrotic focus in invasive breast carcinoma correlates with the expression of carbonic anhydrase IX and is a marker of hypoxia and poor prognosis. Breast Cancer Res Treat 2003;81:137-147.

21 Van den Eynden GG, Van der Auwera I, Van Laere SJ, et al. Angiogenesis and hypoxia in lymph node metastases is predicted by the angiogenesis and hypoxia in the primary tumour in patients with breast cancer. Br J Cancer 2005;93:1128-1136.

22 Bos R, van der Groep P, Greijer AE, et al. Levels of hypoxia-inducible factor-1alpha independently predict prognosis in patients with lymph node negative breast carcinoma. Cancer 2003;97:1573-1581.

23 Bos R, Zhong H, Hanrahan CF, et al. Levels of hypoxiainducible factor-1 alpha during breast carcinogenesis. J Natl Cancer Inst 2001;93:309-314. 
24 Schindl M, Schoppmann SF, Samonigg $\mathrm{H}$, et al. Overexpression of hypoxia-inducible factor 1alpha is associated with an unfavorable prognosis in lymph node-positive breast cancer. Clin Cancer Res 2002;8: 1831-1837.

25 Vleugel MM, Greijer AE, Shvarts A, et al. Differential prognostic impact of hypoxia induced and diffuse HIF1alpha expression in invasive breast cancer. J Clin Pathol 2005;58:172-177.

26 Chia SK, Wykoff CC, Watson PH, et al. Prognostic significance of a novel hypoxia-regulated marker, carbonic anhydrase IX, in invasive breast carcinoma. J Clin Oncol 2001;19:3660-3668.

27 Kornegoor R, Verschuur-Maes AH, Buerger H, et al. Molecular subtyping of male breast cancer by immunohistochemistry. Mod Pathol 2012;25:398-404.

28 Elston CW, Ellis IO. Pathological prognostic factors in breast cancer. I. The value of histological grade in breast cancer: experience from a large study with long-term follow-up. Histopathology 1991;19: 403-410.

29 van Diest PJ, Baak JP, Matze-Cok P, et al. Reproducibility of mitosis counting in 2,469 breast cancer specimens: results from the Multicenter Morphometric Mammary Carcinoma Project. Hum Pathol 1992;23: 603-607.

30 van der Groep P, Bouter A, Menko FH, et al. High frequency of HIF-1alpha overexpression in BRCA1 related breast cancer. Breast Cancer Res Treat 2008; 111:475-480.

31 Harris AL. Hypoxia-a key regulatory factor in tumour growth. Nat Rev Cancer 2002;2:38-47.
32 Bos R, van Diest PJ, de Jong JS, et al. Hypoxiainducible factor-1alpha is associated with angiogenesis, and expression of bFGF, PDGF-BB, and EGFR in invasive breast cancer. Histopathology 2005;46:31-36.

33 Hasebe T, Sasaki S, Imoto S, et al. Highly proliferative fibroblasts forming fibrotic focus govern metastasis of invasive ductal carcinoma of the breast. Mod Pathol 2001;14:325-337.

34 Noel A, Hajitou A, L'Hoir C, et al. Inhibition of stromal matrix metalloproteases: effects on breast-tumor promotion by fibroblasts. Int J Cancer 1998;76:267-273.

35 Afzal S, Lalani EN, Poulsom R, et al. MT1-MMP and MMP-2 mRNA expression in human ovarian tumors: possible implications for the role of desmoplastic fibroblasts. Hum Pathol 1998;29:155-165.

36 Hasebe T, Sasaki S, Imoto S, et al. Proliferative activity of intratumoral fibroblasts is closely correlated with lymph node and distant organ metastases of invasive ductal carcinoma of the breast. Am J Pathol 2000;156: 1701-1710.

37 Zhong H, De Marzo AM, Laughner E, et al. Overexpression of hypoxia-inducible factor 1alpha in common human cancers and their metastases. Cancer Res 1999;59:5830-5835.

38 Laughner E, Taghavi P, Chiles $\mathrm{K}$, et al. HER2 (neu) signaling increases the rate of hypoxia-inducible factor 1alpha (HIF-1alpha) synthesis: novel mechanism for HIF-1-mediated vascular endothelial growth factor expression. Mol Cell Biol 2001;21:3995-4004.

39 van Diest PJ, Vleugel MM, van der Wall E. Expression of HIF-1alpha in human tumours. J Clin Pathol 2005;58:335-336. 